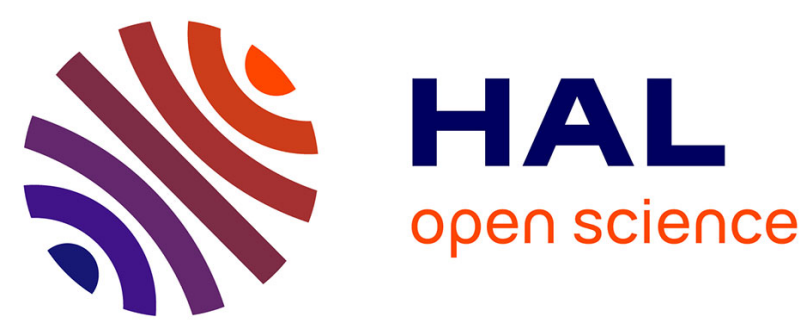

\title{
Environmental radiofrequency electromagnetic field levels in a department of pediatrics
}

Dimitri Besset, Brahim Selmaoui, Pierre Tourneux, André Leke, Stéphane Delanaud, René de Seze, Erwan Stephan

\section{- To cite this version:}

Dimitri Besset, Brahim Selmaoui, Pierre Tourneux, André Leke, Stéphane Delanaud, et al.. Environmental radiofrequency electromagnetic field levels in a department of pediatrics. Environmental Research, 2020, 181, pp.108894. 10.1016/j.envres.2019.108894 . ineris-03229713

\section{HAL Id: ineris-03229713}

\section{https://hal-ineris.archives-ouvertes.fr/ineris-03229713}

Submitted on 3 Aug 2021

HAL is a multi-disciplinary open access archive for the deposit and dissemination of scientific research documents, whether they are published or not. The documents may come from teaching and research institutions in France or abroad, or from public or private research centers.
L'archive ouverte pluridisciplinaire HAL, est destinée au dépôt et à la diffusion de documents scientifiques de niveau recherche, publiés ou non, émanant des établissements d'enseignement et de recherche français ou étrangers, des laboratoires publics ou privés. 


\section{Environmental radiofrequency electromagnetic field levels in a department of pediatrics}

Dimitri BESSET ${ }^{a}$, Brahim SELMAOUI $^{a}$, Pierre TOURNEUX ${ }^{\mathrm{a}}{ }^{\mathrm{b}}$, André LEKE $^{\mathrm{a} b}$, Stephane DELANAUD ${ }^{\mathrm{a}}$, René de SEZE ${ }^{a}$, Erwan STEPHAN-BLANCHARD ${ }^{a}$

a PériTox-INERIS Laboratory UMR_I 01, Jules Verne University of Picardy, Amiens, France

${ }^{\mathrm{b}}$ Neonatal Intensive Care Unit, CHU Amiens-Picardie, F-80000 Amiens, France

Corresponding author:

Dr Erwan STEPHAN-BLANCHARD,

Phone: +33-322-827-897

erwan.stephan@u-picardie.fr 


\section{Highlights:}

- Mean radiofrequency levels measured in a neonatal intensive care unit were low, relative to current guidelines.

- Peak values in mobile phone frequencies were detected.

- Radiofrequency emissions by medical devices were very low. 


\section{Abstract}

Preterm neonates constitute a vulnerable population that is highly sensitive to its environment. Given the increased use of wireless communication devices (mobile and digital enhanced cordless telecommunications, WiFi networks, etc.), neonates hospitalized in a department of pediatrics are potentially exposed to radiofrequency electromagnetic fields (RF-EMF). Strikingly, data on RF-EMF levels in pediatric units have not previously been published.

The objective of the present study was thus to quantify the RF-EMF levels in a 34-bed tertiary department of pediatrics with a neonatal critical care unit (NCCU) and a neonatal intensive care unit (NICU). To this end, we used triaxle antenna dosimeters to map the RF-EMF levels in the environment and to measure spot emissions from medical devices. In a first set of experiments, RFEMF levels at 144 points in the staff area and in the children's rooms in the NCCU and NICU were evaluated over a 24-hour period. In a second set of measurements performed in a Faraday chamber, we measured the RF-EMF levels emitted by the medical devices to which neonates are potentially exposed in the department of pediatrics.

The RF-EMF levels were significantly higher in the NCCU than in the NICU $(p<0.05)$. Although the two units did not differ significantly with regard to the average maximum values, the single greatest value recorded in the NCCU (6 V/m GSM + UMTS 900 (UL) frequency band, in the staff area) was more than twice that recorded in the NICU $(3.70 \mathrm{~V} / \mathrm{m}$ in the UMTS 2100 (UL) frequency band, in the children's rooms). The NCCU and NICU did not differ significantly with regard to the time during which the RFEMF level at each measurement point was more than two standard deviations above its mean. The RF-EMF level was significantly higher during the day than during the night $(p<0.001)$. The various medical devices used in the NICU did not emit detectable amounts of RF.

Overall, RF-EMF levels in the NCCU and NICU were very low. It is probable that the RF-EMFs measured here were primarily generated by the parents' and staff members' activities, rather than by medical devices. However, a combination of low-level, chronic exposure with transient, elevated peak values in a vulnerable population of preterm neonates may be of particular concern. In a department of pediatrics, decreasing preterm neonates' exposure to RF-EMFs should primarily involve a limitation on the use of wireless communication devices by staff members and parents.

\section{Keywords:}

preterm infant, radiofrequency electromagnetic fields, neonatal intensive care unit 


\section{Introduction}

The World Health Organization defines prematurity as a live birth before 37 weeks of gestation (Althabe et al., 2012). The prevalence of preterm infants is increasing as a result of a greater incidence of preterm births and higher survival rates (Msall and Tremont, 2002). Preterm infants require respiratory, hemodynamic, and nutritional support with optimal growth (Glendinning et al., 2001), together with parental commitment to developmental care (O'Brien et al., 2013).

$\mathrm{Hi}$-tech devices are increasingly used in medical care. Although these devices improve the quality of care, they can potentially expose patients and healthcare professionals to electromagnetic fields (EMF). This is especially true in neonatal intensive care units (NICU), where many sources of radiofrequency electromagnetic fields (RF-EMF) are present: mobile phones that use the Global System for Mobile Communications (GSM) and Universal Mobile Telecommunications System (UMTS) standard, cordless phones that use the Digital Enhanced Cordless Telecommunications (DECT), a specific frequency for emergency calls (Calvente et al., 2017), and new-generation monitoring devices that connect to Wireless Fidelity (WiFi) networks, for example.

However, very few studies have analyzed the extent of EMF exposure in preterm neonates. Most of the research to date has focused on extremely low frequency EMF (ELF-EMF; 0-100 kHz). It has been reported that exposure to ELF-EMF was associated with changes in a neonate's autonomic nervous activity and a transient increase in melatonin production (Bellieni et al., 2012). These results raise questions about the potential influence of RF-EMF exposure on outcomes in preterm neonates.

Preterm neonates may be particularly vulnerable to RF-EMF exposure, as a result of their physiological immaturity (Paliwoda et al., 2018) - especially with regard to the central nervous system (CNS) (Modrzejewska and Kot, 2016) - and high sensitivity to the NICU environment (Maki et al., 2017). Specifically the proliferation, differentiation and connections of neurons in the CNS are vulnerable to environmental factors (Blackburn, 2009a, 2009b). Furthermore, the lower skull bone density and higher water content in a child's brain (relative to an adult's) enables RF-EMF energy to penetrate more deeply into tissue (Christ et al., 2010). Moreover, some very-low-birth-weight preterm neonates will have to stay in the NICU for a prolonged period - perhaps up to 100 days (Ancel et al., 2015) - and so will potentially be exposed to high EMF levels during their growth (Lai and Bearer, 2008).

Li et al.(2015) considered that the safety limits prescribed by the International Commission on NonIonizing Radiation Protection (ICNIRP, 1998) may not be suitable for the exposure of preterm neonates to RF-EMF (Li et al., 2015). Furthermore, current EMF safety levels are based on literature 
data on the short-term risk, whereas a large number of diseases may have a long latency period (Calvente et al., 2015).

A few studies have shown that neonates are exposed to ELF-EMF inside incubators, with peak levels of magnetic flux density ranging from $8.84 \mu \mathrm{T}$ (Bellieni et al., 2012) to $74.56 \mu \mathrm{T}$. ELF-EMF levels in the NICU's general environment were found to be lower, with values ranging from 0.1 to $0.2 \mu$ T (Aasen et al., 1996; Riminesi et al., 2004). One recent study reported on levels of RF-EMF in the frequency band between $87.5 \mathrm{MHz}$ and $5.8 \mathrm{GHz}$, although it focused on measurements in a small neonatal medium care unit (Calvente et al., 2017). To the best of our knowledge, data on RF-EMF levels to which preterm neonates may be exposed during their stay in a NICU are not available in the literature.

The objective of the present study was thus to quantify the levels of RF-EMF levels in a NICU by mapping the RF-EMF distribution in the staff area and in children's rooms and by measuring spot emissions from various medical devices switched on. We expected that this would enable us to (i) better characterize the sources and conditions of exposure, and (ii) provide new data about the actual levels to which preterm neonates might be exposed during their stay in the NICU. 


\section{Materials and Methods}

\section{Study area}

RF-EMF levels were measured in the Department of Pediatrics at Amiens University Medical Center (Amiens, France) between March 26 $6^{\text {th }}, 2018$, and October 18 $18^{\text {th }}, 2018$ (Appendix 1). The department was inaugurated in September 2014, and comprises two different units: a 18-bed neonatal critical care unit (NCCU) for children born before 32 weeks of gestation or after 32 weeks of gestation but requiring hemodynamic and/or invasive ventilatory support, and a 16-bed neonatal intensive care unit (NICU). Measurements were made in the department's staff area and in the preterm children's rooms. No changes in the service's activities (either the medical staff or visitors) were implemented.

\section{Equipment}

Four dosimeters (EME Spy 200, Microwave Vision Group, Paris, France) were used to measure the RF-EMF in 20 different frequency bands from $88 \mathrm{MHz}$ to $5850 \mathrm{MHz}$ (Table 1) and thus calculate the total RF-EMF exposure (i.e. the quadratic sum of the RF values in the different frequency bands). The EME Spy 200 dosimeter senses EMF via three orthogonally arranged antennae, with a sensitivity ranging from $0.01 \mathrm{~V} / \mathrm{m}$ to $6 \mathrm{~V} / \mathrm{m}$ (FM, TV3, TETRA, TV4\&5 and WiFi $5 \mathrm{G}$ ) and from $0.005 \mathrm{~V} / \mathrm{m}$ to $6 \mathrm{~V} / \mathrm{m}$ (LTE 800, GSM, DCS, DECT, UMTS, WiFi 2G, LTE 2600, and WiMax).

\begin{tabular}{|l|l|l|l|}
\hline FM & $87-107 \mathrm{MHz}$ & GSM $1800(\mathrm{UL})$ & $1710-1785 \mathrm{MHz}$ \\
\hline TV3 & $174-223 \mathrm{MHz}$ & GSM $1800(\mathrm{DL})$ & $1805-1880 \mathrm{MHz}$ \\
\hline TETRA I & $380-400 \mathrm{MHz}$ & DECT & $1880-1900 \mathrm{MHz}$ \\
\hline TETRA II & $410-430 \mathrm{MHz}$ & UMTS 2100 (UL) & $1920-1980 \mathrm{MHz}$ \\
\hline TETRA III & $450-470 \mathrm{MHz}$ & UMTS 2100 (DL) & $2110-2170 \mathrm{MHz}$ \\
\hline TV4\&5 & $470-770 \mathrm{MHz}$ & WiFi 2G & $2400-2483.5 \mathrm{MHz}$ \\
\hline LTE 800 (DL) & $791-821 \mathrm{MHz}$ & LTE 2600 (UL) & $2500-2570 \mathrm{MHz}$ \\
\hline LTE 800 (UL) & $832-862 \mathrm{MHz}$ & LTE 2600 (DL) & $2620-2690 \mathrm{MHz}$ \\
\hline GSM + UMTS 900 (UL) & $880-915 \mathrm{MHz}$ & WIMAX & $3300-3900 \mathrm{MHz}$ \\
\hline GSM + UMTS 900 (DL) & $925-960 \mathrm{MHz}$ & WiFi 5G & $5150-5850 \mathrm{MHz}$ \\
\hline
\end{tabular}

Table 1: Bands in the RF spectrum 


\section{Measurement procedures}

\subsection{Measurements in staff areas and children's rooms}

In a first set of experiments, we measured RF-EMF levels in the NCCU and NICU's staff areas. The department of pediatrics was mapped in order to get the best possible representation of the distribution of the electromagnetic fields. The measurement sites $(n=194)$ were defined on a standard map $(1 \times 1 \mathrm{~m})$ and adjusted according to the configuration of the premises. The dosimeters were placed throughout the department in a pseudo-random manner while avoiding the possibility of simultaneous side-by-side measurements. The dosimeter was set vertically on a tripod at a height of $110 \mathrm{~cm}$ from the floor (corresponding to the height of a preterm infant in an incubator). Measurements were recorded every $20 \mathrm{~s}$ for 24 hours, representing 4231 points per day. The dosimeters were moved every 24 hours. For each measurement point, the values recorded over 24 hours were averaged (63 in the NCCU's staff area, and 56 in the NCCU's staff area).

In the preterm infants' rooms, measurements over 24 hours were made by placing three dosimeters at various points around the incubator. The three measurements were averaged over 24 hours to give a single value per room and per day (13 in the NCCU's children's rooms, and 12 in the NCCU's children's rooms).

\subsection{Measurements of medical devices used in the department}

In a second set of experiments, we used a Faraday chamber to determine whether various medical devices frequently used in the children's rooms (e.g. incubators and monitoring devices) were potential sources of exposure to RF-EMF. The levels emitted by the operating devices (i.e. in the "on" position) were measured one by one every 4 second for 3 minutes in the Faraday chamber. For measurements inside incubators, three dosimeters were placed at the usual position of the feet, abdomen and head. These three values were averaged to provide a single value per incubator. The dosimeter was placed as close as possible to the other devices investigated (transport monitors, phototherapy devices, warmers, respirators, syringe drivers, and milk syringe drivers). 


\section{Statistics}

For each of the 144 measurement points, the maximum value and the mean value over 24 hours were calculated. The maximum values were averaged over all the measurement points. The single greatest value was also extracted. Furthermore, we calculated the time during which the RF-EMF level at each measurement point was more than two standard deviations (SDs) above its mean.

All statistical analyses were performed with Statview software (SAS Institute, Inc., Cary, NC). The threshold for statistical significance was set to $p<0.05$. The normality of the data distribution was checked by applying the Kolmogorov Smirnov test. Differences (between the NCCU and the NICU, between staff areas and children's rooms, and between daytime and night-time) were probed using a t-test or (for non-normally distributed data) the Mann-Whitney test. 


\section{Results}

The 24-hour RF-EMF levels in the staff area vs. the children's rooms in the NCCU and in the NICU are shown in

Figure 1. In the NCCU, the mean \pm SD RF-EMF levels were significantly higher in the staff area $(0.05 \pm$ $0.02 \mathrm{~V} / \mathrm{m} ; \mathrm{n}=63$ measurement points) than in the children's rooms $(0.03 \pm 0.01 \mathrm{~V} / \mathrm{m}, \mathrm{n}=13 ; \mathrm{p}$ $<0.0011)$. In the NICU, there was no difference between the staff area $(0.03 \pm 0.01 \mathrm{~V} / \mathrm{m}, \mathrm{n}=56)$ and the children's rooms $(0.03 \pm 0.01 \mathrm{~V} / \mathrm{m}, \mathrm{n}=12)$. The values for the staff areas and the children's rooms were pooled for the NCCU and the NICU. The mean \pm SD RF-EMF levels were significantly higher in the NCCU $(0.04 \pm 0.02 \mathrm{~V} / \mathrm{m} ; \mathrm{n}=76$ measurement points) than in the NICU $(0.03 \pm 0.01 \mathrm{~V} / \mathrm{m}, \mathrm{n}=68 ; \mathrm{p}$ $<0.0001)$.
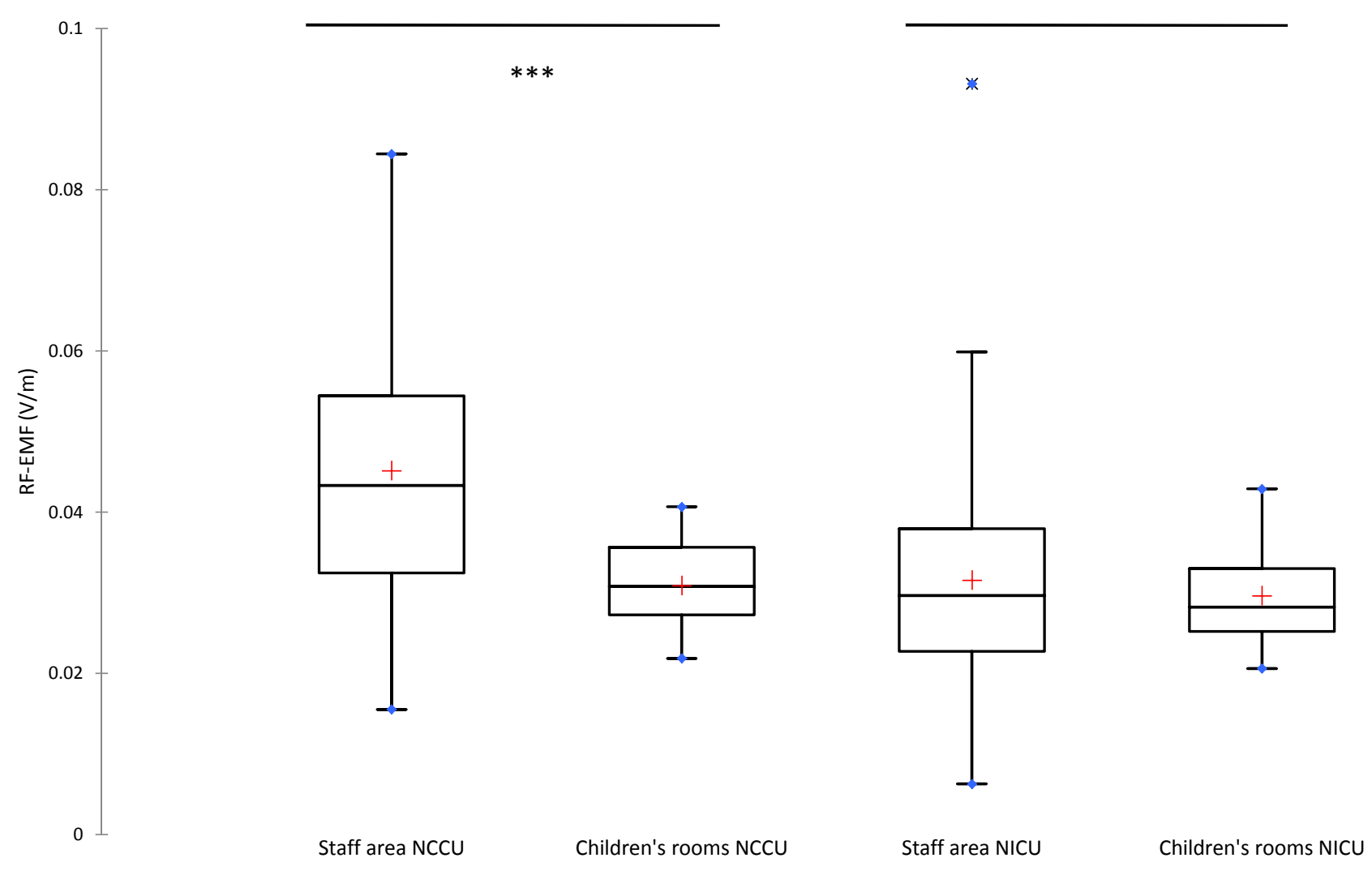

Figure 1: 24-hour RF-EMF levels in the staff area and children's rooms for the NCCU and the NICU. The cross indicates the mean value. 
The time during which the RF-EMF level was more than 2 SDs above the 24-h mean for the NICU and the NCCU (for the 20 frequency bands, and in total) is shown in Figure 2. Overall, the mean \pm SD values did not differ significantly when comparing the NCCU and the NICU ( $48 \pm 15 \mathrm{~min}, \mathrm{n}=76$, and 49 $\pm 14 \mathrm{~min}, \mathrm{n}=68$, respectively; $\mathrm{p}=0.81$ ). However, there significant differences between the two units for the TETRA I, TETRA III, LTE 800 (UL), GSM + 900 (UL), DECT, WiFi 2G, LTE 2600 (UL), and WiFi 5 G bands.

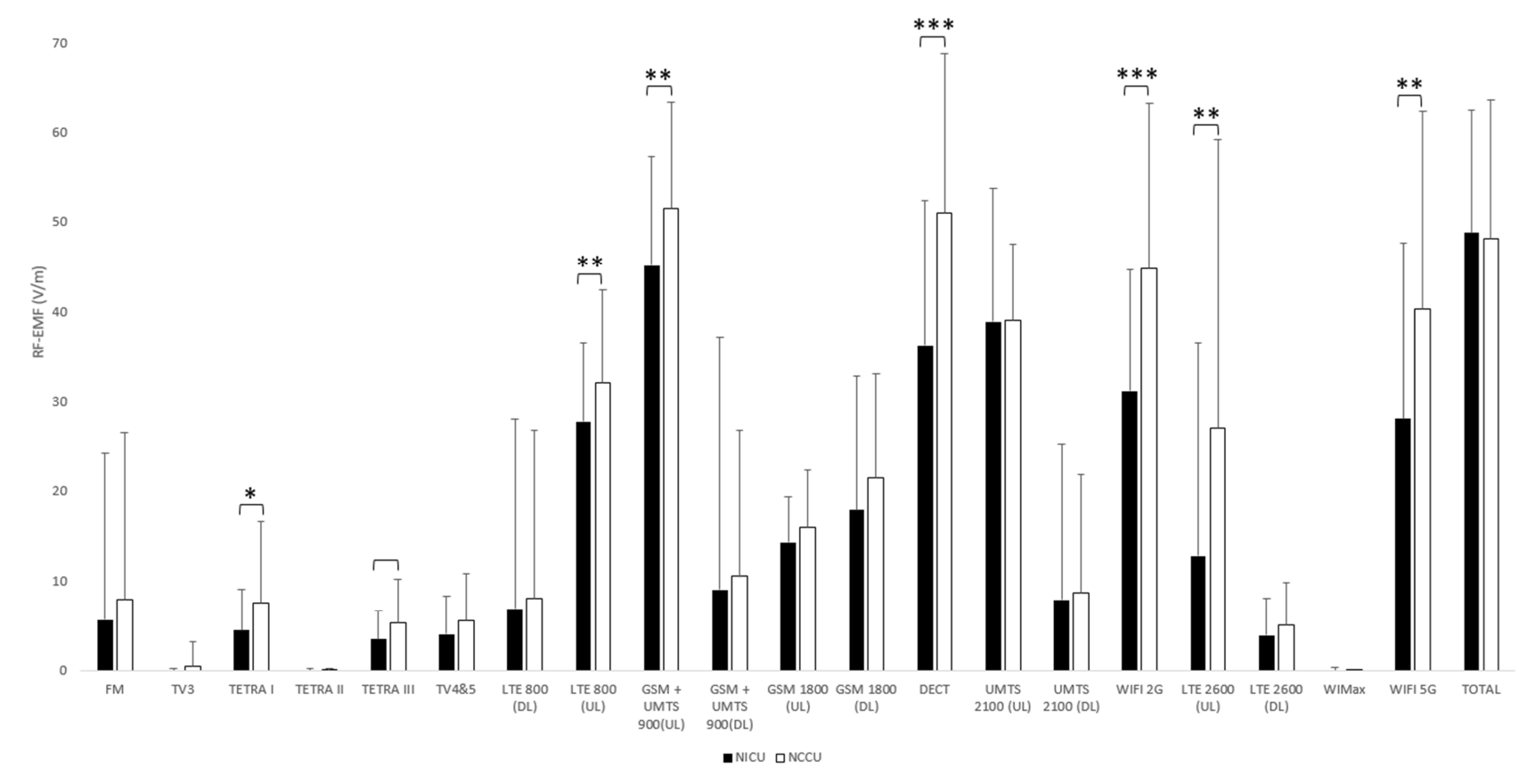

Figure 2: Time during which the RF-EMF level was more than 2 SDs above the 24-h mean for the NICU and the NCCU.

The NCCU and NICU did not differ significantly with regard to the average maximum values for the whole set of measurement points ( $1.08 \pm 0.87$ vs. $0.93 \pm 0.68 \mathrm{~V} / \mathrm{m}$, respectively; $\mathrm{p}=0.52)$. The single greatest value recorded in the NCCU saturated the dosimeter $(6.0 \mathrm{~V} / \mathrm{m}$ for the GMS + UMTS 900 (UL) frequency bands in the staff area) and was notably greater than the single greatest value recorded in the NICU (3.7 V/m for the UMTS 2100 (UL) frequency band in the children's rooms).

In the NCCU, there was a significant difference between RF-EMF levels during the night $(0.04 \pm 0.04$ $\mathrm{V} / \mathrm{m})$ and during the day $(0.05 \pm 0.05 \mathrm{~V} / \mathrm{m} ; \mathrm{p}<0.001)$ (Figure 3). The same was true for the NICU, with a value of $0.03 \pm 0.04 \mathrm{~V} / \mathrm{m}$ during the night and $0.04 \pm 0.05 \mathrm{~V} / \mathrm{m}$ during the day $(p<0.0001)$. It is noteworthy that the single greatest values were recorded during the night for both the NCCU and NICU. The single greatest values recorded during the day was $3.0 \mathrm{~V} / \mathrm{m}$ (for the UMTS 2100 (UL) 
frequency band in the staff area) in the NCCU and $1.9 \mathrm{~V} / \mathrm{m}$ (for the GMS + UMTS 900 (UL) frequency band in the staff area) in the NICU.
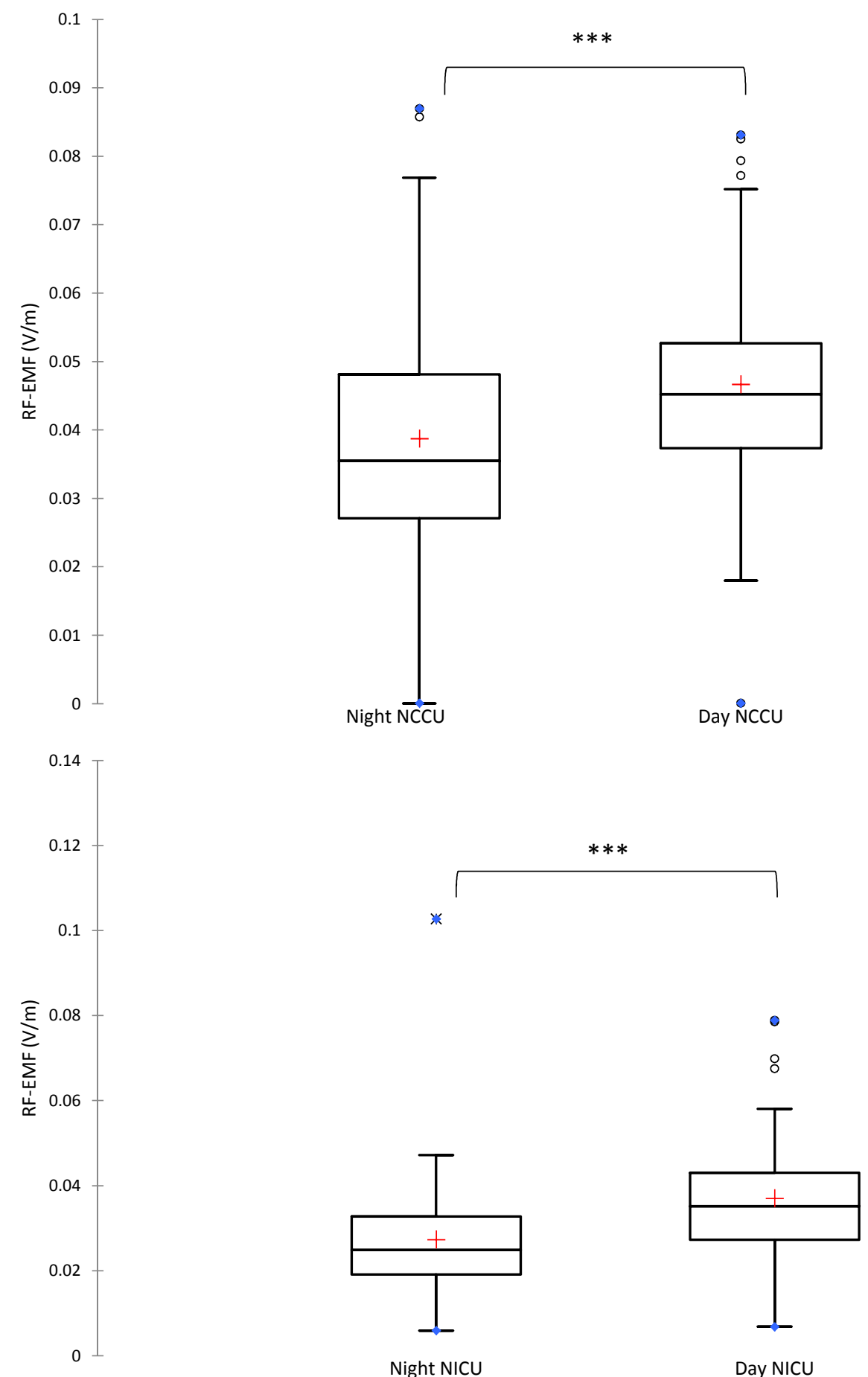

Figure 3: RF-EMF levels by period of the day (night-time: 6 pm to 8 am; daytime: 8 am to $6 \mathrm{pm}$ ). The cross indicates the mean. 
In the second set of experiments (performed in a Faraday chamber), the only device to exceed the limit of detection $(0.005 \mathrm{~V} / \mathrm{m})$ was the Mediprema Satis + incubator (Figure 4), for which we noted oscillation in the TV3 band (explaining why a SD is indicated in the Figure 4).

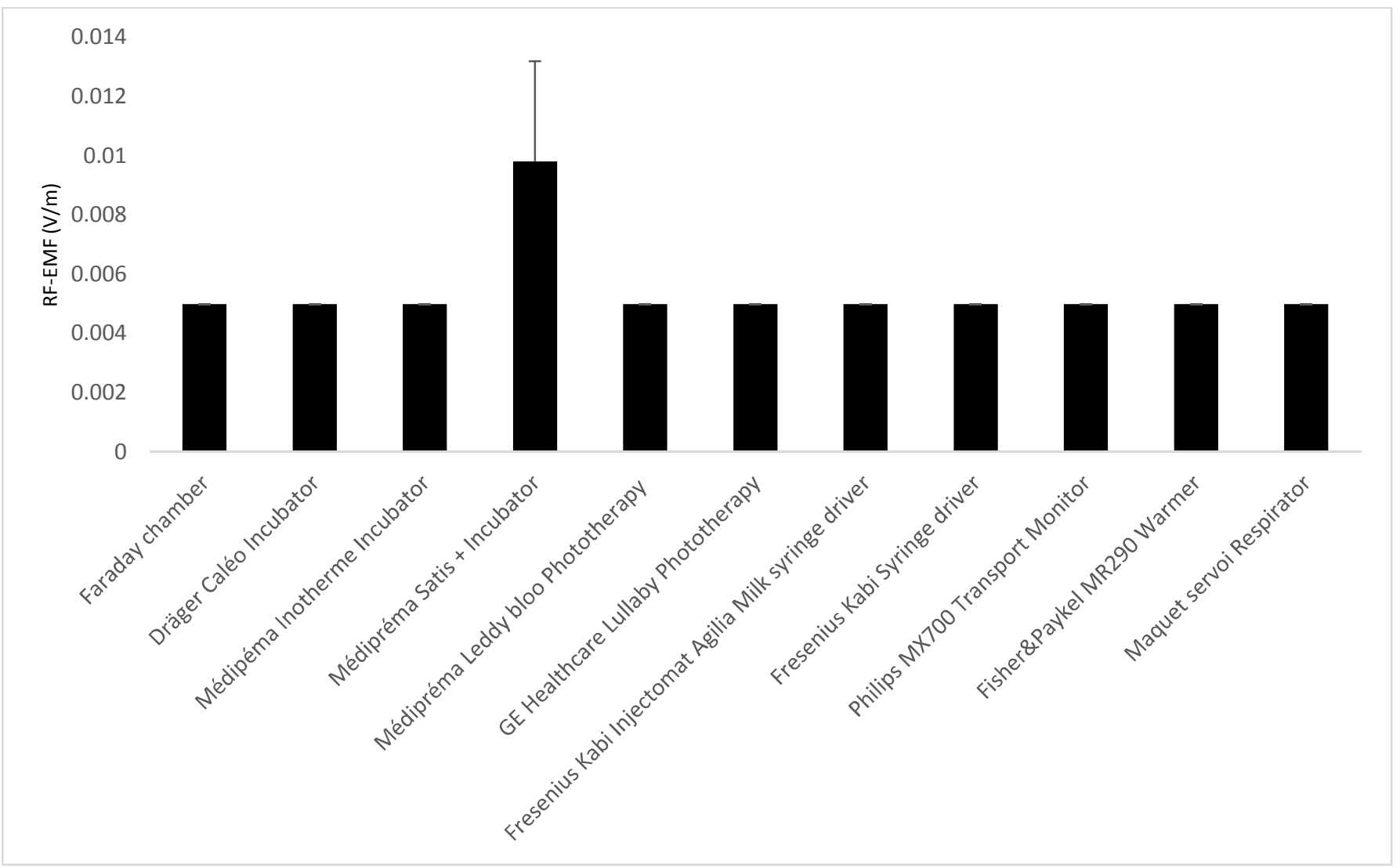

Figure 4: RF-EMF levels emitted by various medical devices in a Faraday chamber 


\section{Discussion:}

Technological developments have resulted in the extensive generation of man-made EMF. The impact of exposure to these EMF on human health is receiving a great deal of attention from scientists and the general public - especially with regard to the exposure of sensitive populations like preterm neonates. A precise evaluation of the type and level of exposure is always an essential preliminary step towards understanding clinical outcomes in detail.

To the best of our knowledge, the present study is the first to have measured RF-EMF levels in a department of pediatrics, including an NCCU and a NICU. Mean RF-EMF levels were significantly higher in the staff area than in the children's rooms for the NCCU $(p<0.0011)$. Overall, levels were also significantly higher in the NCCU than in the NICU RF-EMF ( $p<0.0001)$. Although the two units did not differ significantly with regard to the average maximum values, the single greatest value recorded in the NCCU ( $6 \mathrm{~V} / \mathrm{m}$ for the GSM and UMTS 900 frequency bands in the staff area) was above twice that recorded in the NICU $(3.70 \mathrm{~V} / \mathrm{m}$ for the UMTS 2100 (UL) frequency band in the care area). The NCCU and NICU did not differ significantly with regard to the time during which the RFEMF level was more than two SDs above the mean. Lastly, the RF-EMF level was significantly higher during the day than during the night $(p<0.001)$.

The RF-EMF levels in the present study were lower $(0.04 \pm 0.02 \mathrm{~V} / \mathrm{m})$ than those measured by Calvente et al. (2017) $(0.81 \pm 0.07 \mathrm{~V} / \mathrm{m})$. The high values in Calvente et al.'s study were mainly due to the FM frequency band $(0.79 \mathrm{~V} / \mathrm{m})$. Given that in-hospital medical devices do not emit in the FM band, we conclude that Calvente et al.'s RF-EMF came from outside. Accordingly, the values reported by Calvente (2017) may not accurately reflect the RF-EMF levels related to care activities inside NICU. In our study, the frequency bands with the highest EMF levels were GSM + UMTS 900 (UL) (0.02 \pm $0.009 \mathrm{~V} / \mathrm{m})$ and DECT $(0.02 \pm 0.014 \mathrm{~V} / \mathrm{m})$ in the NICU, and GSM + UMTS 900 (UL) $(0.014 \pm 0.007 \mathrm{~V} / \mathrm{m})$ for the NCCU. There are several possible explanations for the low overall RF-EMF levels measured here. Firstly, our hospital was built recently (in 2014). Secondly, and although the department of pediatrics is equipped with modern devices that can communicate via WiFi networks, the hospital decided to used wired communication exclusively. Lastly, the hospital is located on the outskirts of the city of Amiens (i.e. close to the countryside) and it is not close to any telecommunications masts. We therefore hypothesize that RF-EMF levels in hospitals are site-dependent in terms of the sources (modern vs. older buildings) and prevention policy (e.g. wired vs. wireless)

Our study did not include an analysis of levels of activity in the units: this prevented us from precisely identifying the sources of the RF-EMF. Nevertheless, our measurements in a Faraday chamber showed that none of the tested medical devices emitted RF-EMF levels. One can therefore conclude 
that the RF-EMF measured in the children's rooms were generated elsewhere (i.e. in staff areas, corridors, etc.). It is possible to determine the emission sources indirectly via an assessment of the frequency bands during the day (when most care activities take place) and the night. The RF-EMF level was significantly higher during the day than during the night. We hypothesize that this difference was mainly due to use of the parents' and carers' mobile and cordless phones during the day because the preponderant frequency bands were in the GSM + UMTS 900 (UL) and DECT bands. In contrast, the average maximum values (in the GSM + UMTS 900 (UL) and UMTS 2100 (UL) bands) were greater at night, and were perhaps related to phone use; given the lower levels of care activity at night, the parents and staff present may have had more time to consult their phone - as already suggested by Calvente et al. (2017). Our present data consolidate the hypothesis whereby the RFEMF levels detected within the department of pediatrics were mainly due to wireless communication systems used during routine care activities. A subsequent experiment in the Faraday chamber (data not shown) showed that a DECT phone used in the department was associated with a mean field of $0.743 \pm 0.192 \mathrm{~V} / \mathrm{m}$ over an hour. Under these conditions, the device was constantly searching for a signal and so this operation might also account for the high values that we recorded.

Overall, the measured RF-EMF levels were very low $(<0.1 \mathrm{~V} / \mathrm{m})$; the average in the NCCU $(0.04 \mathrm{~V} / \mathrm{m})$ was around 1250 times lower than the recommended limit of $50 \mathrm{~V} / \mathrm{m}$. Even though the latter value was calculated (ICNIRP, 1998) to take account of the population's heterogeneity and frailty, it was not specifically designed for preterm neonates. Moreover, we also observed a single transient greatest RF value of $6 \mathrm{~V} / \mathrm{m}$, corresponding to the dosimeter's saturation level. Hence, we cannot rule out the possibility that even higher RF-EMF levels were produced at some point.

The presence of these high peak values raises the question of their potential impact on the neurodevelopmental outcome of preterm infants. At present, there are no literature data on putative effects of RF peaks. However, children (and especially preterm neonates) may be particularly vulnerable to RF exposure. The most frequently suggested reasons are the vulnerability of the developing CNS (Blackburn, 2009a, 2009b), the greater absorption of RF energy (relative to adults) (Fernández et al., 2018), and the longer period of lifetime exposure (i.e. starting at birth or even before). The greater absorption of RF-EMF energy in children is attributed to a higher tissue water content (vs. adults) and thus differences in dielectric values (conductivity and permittivity) (Christ et al., 2010). In a study of a porcine model, the dielectric properties of brain tissues were found to be significantly greater in young animals than in adult animals (up to $43 \%$, for white matter) (Peyman, 2011). At a given frequency, the radiation penetrates more deeply and spreads more widely within a child's brain than within an adult's brain (Fernández et al., 2018). 


\section{Conclusions}

The present study is the first to have measured environmental RF-EMF levels in a department of pediatrics' NCCU and NICU. The levels were low, relative to current guidelines. However, a combination of low-level, chronic exposure with transient, elevated peak values in a vulnerable population of preterm neonates may be of particular concern. In a department of pediatrics, decreasing preterm neonates' exposure to RF-EMF should primarily involve a limitation on the use of wireless communication devices by staff members and parents. Even though some earlier research (Bellieni et al., 2012, 2008) has focused on the potential danger of low-frequency EMF, the impact of chronic RF-EMF exposure on the physiological and/or developmental trajectory in preterm neonates now warrants investigation.

\section{Acknowledgments}

The authors thank the staff of the Neonatology Department for their assistance with the experiments. They also wish to thank David Fraser (Biotech Communication SARL, Ploudalmézeau, France) for copy-editing assistance.

\section{Funding}

This work was funded by the French National Research Program for Environmental and Occupational Health of ANSES (EST/2017/2 RF/03). 


\section{References}

Aasen, S.E., Johnsson, A., Bratlid, D., Christensen, T., 1996. Fifty-Hertz magnetic field exposures of premature infants in a neonatal intensive care unit. Biol. Neonate 70, 249-264. https://doi.org/10.1159/000244374

Althabe, F., Howson, C.P., Kinney, M., Lawn, J., World Health Organization, 2012. Born too soon: the global action report on preterm birth.

Ancel, P.-Y., Goffinet, F., Kuhn, P., Langer, B., Matis, J., Hernandorena, X., Chabanier, P., JolyPedespan, L., Lecomte, B., Vendittelli, F., Dreyfus, M., Guillois, B., Burguet, A., Sagot, P., Sizun, J., Beuchée, A., Rouget, F., Favreau, A., Saliba, E., Bednarek, N., Morville, P., Thiriez, G., Marpeau, L., Marret, S., Kayem, G., Durrmeyer, X., Granier, M., Baud, O., Jarreau, P.-H., Mitanchez, D., Boileau, P., Boulot, P., Cambonie, G., Daudé, H., Bédu, A., Mons, F., Fresson, J., Vieux, R., Alberge, C., Arnaud, C., Vayssière, C., Truffert, P., Pierrat, V., Subtil, D., D'Ercole, C., Gire, C., Simeoni, U., Bongain, A., Sentilhes, L., Rozé, J.-C., Gondry, J., Leke, A., Deiber, M., Claris, O., Picaud, J.-C., Ego, A., Debillon, T., Poulichet, A., Coliné, E., Favre, A., Fléchelles, O., Samperiz, S., Ramful, D., Branger, B., Benhammou, V., Foix-L'Hélias, L., Marchand-Martin, L., Kaminski, M., 2015. Survival and Morbidity of Preterm Children Born at 22 Through 34 Weeks' Gestation in France in 2011: Results of the EPIPAGE-2 Cohort Study. JAMA Pediatr. 169, 230. https://doi.org/10.1001/jamapediatrics.2014.3351

Bellieni, C.V., Acampa, M., Maffei, M., Maffei, S., Perrone, S., Pinto, I., Stacchini, N., Buonocore, G., 2008. Electromagnetic fields produced by incubators influence heart rate variability in newborns. Arch. Dis. Child. Fetal Neonatal Ed. 93, F298-301. https://doi.org/10.1136/adc.2007.132738

Bellieni, C.V., Tei, M., lacoponi, F., Tataranno, M.L., Negro, S., Proietti, F., Longini, M., Perrone, S., Buonocore, G., 2012. Is newborn melatonin production influenced by magnetic fields produced by incubators? Early Hum. Dev. 88, 707-710. https://doi.org/10.1016/j.earlhumdev.2012.02.015

Blackburn, S., 2009a. Central nervous system vulnerabilities in preterm infants, part I. J. Perinat. Neonatal Nurs. 23, 12-14. https://doi.org/10.1097/JPN.0b013e31819685cc

Blackburn, S., 2009b. Central nervous system vulnerabilities in preterm infants, part II. J. Perinat. Neonatal Nurs. 23, 108-110. https://doi.org/10.1097/JPN.0b013e3181a3924b

Calvente, I., Fernández, M.F., Pérez-Lobato, R., Dávila-Arias, C., Ocón, O., Ramos, R., Ríos-Arrabal, S., Villalba-Moreno, J., Olea, N., Núñez, M.I., 2015. Outdoor characterization of radio frequency electromagnetic fields in a Spanish birth cohort. Environ. Res. 138, 136-143. https://doi.org/10.1016/j.envres.2014.12.013

Calvente, I., Vázquez-Pérez, A., Fernández, M.F., Núñez, M.I., Múñoz-Hoyos, A., 2017. Radiofrequency exposure in the Neonatal Medium Care Unit. Environ. Res. 152, 66-72. https://doi.org/10.1016/j.envres.2016.09.019

Christ, A., Gosselin, M.-C., Christopoulou, M., Kühn, S., Kuster, N., 2010. Age-dependent tissuespecific exposure of cell phone users. Phys. Med. Biol. 55, 1767-1783. https://doi.org/10.1088/0031-9155/55/7/001

Decima, P.F.F., Fyfe, K.L., Odoi, A., Wong, F.Y., Horne, R.S.C., 2015. The longitudinal effects of persistent periodic breathing on cerebral oxygenation in preterm infants. Sleep Med. 16, 729-735. https://doi.org/10.1016/j.sleep.2015.02.537

Fernández, C., de Salles, A.A., Sears, M.E., Morris, R.D., Davis, D.L., 2018. Absorption of wireless radiation in the child versus adult brain and eye from cell phone conversation or virtual reality. Environ. Res. 167, 694-699. https://doi.org/10.1016/j.envres.2018.05.013

Glendinning, C., Kirk, S., Guiffrida, A., Lawton, D., 2001. Technology-dependent children in the community: definitions, numbers and costs. Child Care Health Dev. 27, 321-334. 
ICNIRP, 1998. Guidelines of limiting exposure to time-varying electric, magnetic, and electromagnetic fields (up to $300 \mathrm{GHz}$ ) [WWW Document]. URL https://www.icnirp.org/cms/upload/publications/ICNIRPemfgdl.pdf (accessed 1.9.19).

Lai, T.T., Bearer, C.F., 2008. latrogenic Environmental Hazards in the Neonatal Intensive Care Unit. Clin. Perinatol. 35, 163-181. https://doi.org/10.1016/j.clp.2007.11.003

Li, C., Chen, Z., Yang, L., Lv, B., Liu, J., Varsier, N., Hadjem, A., Wiart, J., Xie, Y., Ma, L., Wu, T., 2015. Generation of infant anatomical models for evaluating electromagnetic field exposures: Infant Models for EMF Evaluation. Bioelectromagnetics 36, 10-26. https://doi.org/10.1002/bem.21868

Maki, M.T., Orsi, K.C.S.C., Tsunemi, M.H., Hallinan, M.P., Pinheiro, E.M., Avelar, A.F.M., 2017. O efeito da manipulação sobre o sono do recém-nascido prematuro. Acta Paul. Enferm. 30, 489-496. https://doi.org/10.1590/1982-0194201700071

Modrzejewska, M., Kot, J., 2016. Changes in the central nervous system of prematurely born children. Klin. Oczna 118, 55-58.

Msall, M.E., Tremont, M.R., 2002. Measuring functional outcomes after prematurity: developmental impact of very low birth weight and extremely low birth weight status on childhood disability. Ment. Retard. Dev. Disabil. Res. Rev. 8, 258-272. https://doi.org/10.1002/mrdd.10046

O’Brien, K., Bracht, M., Macdonell, K., McBride, T., Robson, K., O'Leary, L., Christie, K., Galarza, M., Dicky, T., Levin, A., Lee, S.K., 2013. A pilot cohort analytic study of Family Integrated Care in a Canadian neonatal intensive care unit. BMC Pregnancy Childbirth 13, S12. https://doi.org/10.1186/1471-2393-13-S1-S12

Paliwoda, M., New, K., Davies, M., Bogossian, F., 2018. Physiological vital sign ranges in newborns from 34 weeks gestation: A systematic review. Int. J. Nurs. Stud. 77, 81-90. https://doi.org/10.1016/j.ijnurstu.2017.10.004

Peyman, A., 2011. Dielectric properties of tissues; variation with age and their relevance in exposure of children to electromagnetic fields; state of knowledge. Prog. Biophys. Mol. Biol. 107, 434438. https://doi.org/10.1016/j.pbiomolbio.2011.08.007

Riminesi, C., Andreuccetti, D., Fossi, R., Pezzati, M., 2004. ELF magnetic field exposure in a neonatal intensive care unit. Bioelectromagnetics 25, 481-491. https://doi.org/10.1002/bem.20017 


\section{Appendix}

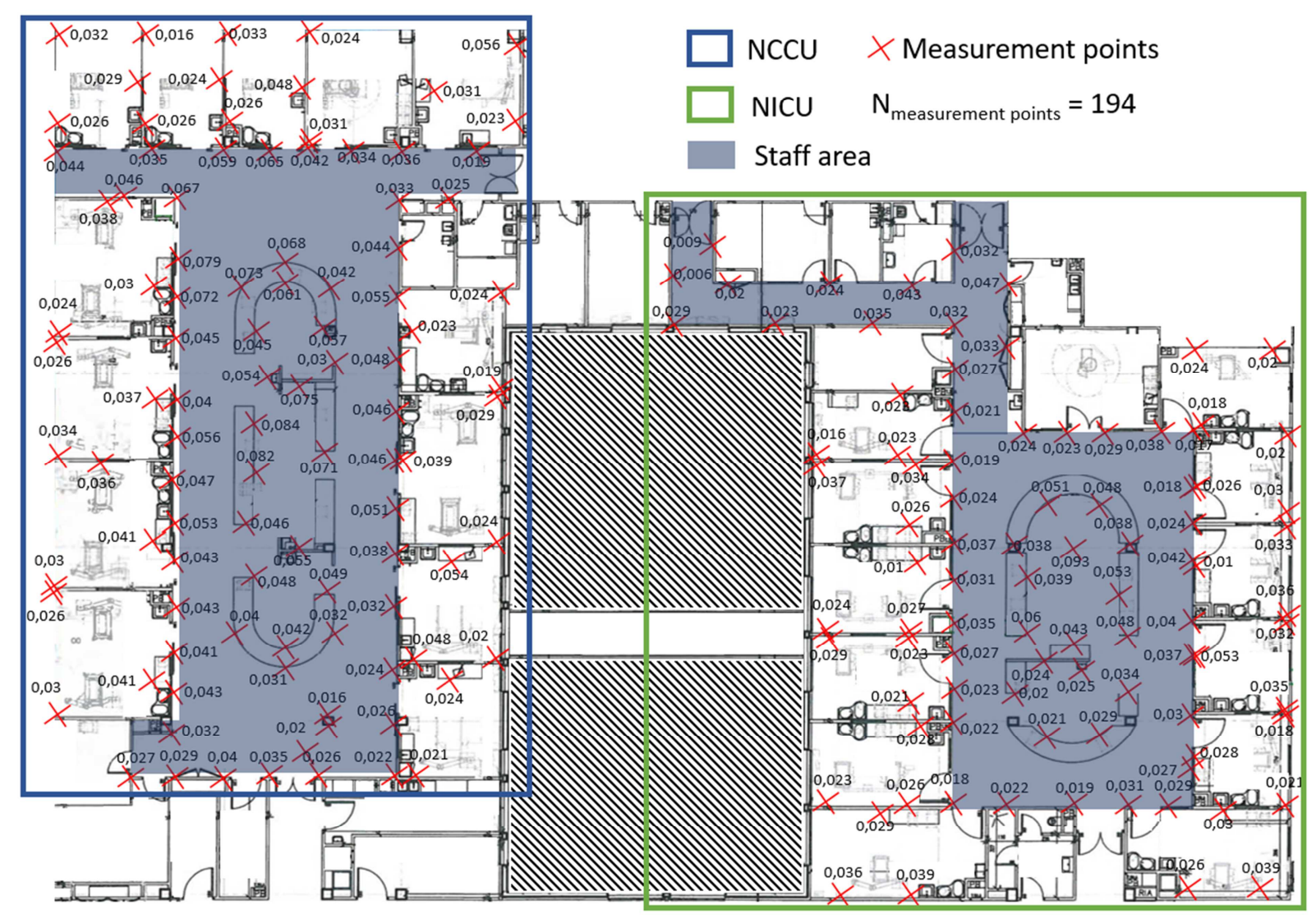

Appendix 1: Floorplan of the NCCU and NICU in the Department of Pediatrics at Amiens University Medical Center (Amiens, France). 


\begin{tabular}{|lllll|}
\hline \multirow{2}{*}{ Frequency band } & NCCU & & NICU & \\
\cline { 2 - 5 } & Staff area & Children's rooms & Staff area & Children's rooms \\
\hline FM & $0.01 \pm 0.000$ & $0.01 \pm 0.001$ & $0.01 \pm 0.000$ & $0.01 \pm 0.000$ \\
\hline TV3 & $0.01 \pm 0.000$ & $0.01 \pm 0.000$ & $0.01 \pm 0.000$ & $0.01 \pm 0.000$ \\
\hline TETRA I & $0.01 \pm 0.001$ & $0.01 \pm 0.001$ & $0.01 \pm 0.001$ & $0.01 \pm 0.001$ \\
\hline TETRA II & $0.01 \pm 0.000$ & $0.01 \pm 0.000$ & $0.01 \pm 0.000$ & $0.01 \pm 0.000$ \\
\hline TETRA III & $0.01 \pm 0.001$ & $0.01 \pm 0.001$ & $0.01 \pm 0.001$ & $0.01 \pm 0.000$ \\
\hline TV4\&5 & $0.01 \pm 0.003$ & $0.01 \pm 0.001$ & $0.01 \pm 0.001$ & $0.01 \pm 0.001$ \\
\hline LTE 800 (DL) & $0.005 \pm 0.000$ & $0.006 \pm 0.001$ & $0.005 \pm 0.000$ & $0.005 \pm 0.000$ \\
\hline LTE 800 (UL) & $0.009 \pm 0.022$ & $0.007 \pm 0.001$ & $0.007 \pm 0.015$ & $0.008 \pm 0.017$ \\
\hline GSM + UMTS 900 (UL) & $0.005 \pm 0.000$ & $0.012 \pm 0.013$ & $0.014 \pm 0.027$ & $0.013 \pm 0.027$ \\
\hline GSM + UMTS 900 (DL) & $0.018 \pm 0.03$ & $0.006 \pm 0.019$ & $0.005 \pm 0.000$ & $0.005 \pm 0.000$ \\
\hline GSM 1800 (UL) & $0.005 \pm 0.001$ & $0.006 \pm 0.000$ & $0.006 \pm 0.008$ & $0.006 \pm 0.010$ \\
\hline GSM 1800 (DL) & $0.006 \pm 0.006$ & $0.006 \pm 0.007$ & $0.005 \pm 0.001$ & $0.005 \pm 0.001$ \\
\hline DECT & $0.023 \pm 0.016$ & $0.011 \pm 0.001$ & $0.011 \pm 0.011$ & $0.009 \pm 0.009$ \\
\hline UMTS 2100 (UL) & $0.005 \pm 0.001$ & $0.011 \pm 0.009$ & $0.011 \pm 0.027$ & $0.013 \pm 0.034$ \\
\hline UMTS 2100 (DL) & $0.011 \pm 0.026$ & $0.005 \pm 0.027$ & $0.005 \pm 0.001$ & $0.005 \pm 0.001$ \\
\hline WiFi 2G & $0.007 \pm 0.003$ & $0.005 \pm 0.001$ & $0.006 \pm 0.003$ & $0.005 \pm 0.001$ \\
\hline LTE 2600 (UL) & $0.005 \pm 0.001$ & $0.005 \pm 0.003$ & $0.005 \pm 0.002$ & $0.005 \pm 0.000$ \\
\hline LTE 2600 (DL) & $0.005 \pm 0.001$ & $0.005 \pm 0.001$ & $0.005 \pm 0.000$ & $0.005 \pm 0.001$ \\
\hline WIMAX & $0.005 \pm 0.000$ & $0.005 \pm 0.000$ & $0.005 \pm 0.000$ & $0.005 \pm 0.000$ \\
\hline WiFi 5G & $0.01 \pm .002$ & $0.01 \pm 0.001$ & $0.01 \pm 0.001$ & $0.01 \pm 0.001$ \\
\hline Total & $0.05 \pm 0.045$ & $0.03 \pm 0.036$ & $0.03 \pm 0.041$ & $0.03 \pm 0.049$ \\
\hline Appendix $2:$ (D) & 0.000 \\
\hline
\end{tabular}

Appendix 2: Mean RF-EMF values for the staff area and children's rooms in the NCCU and NICU. 